\title{
"A fuga de André": uma intervenção psicoterapêutica
}

\author{
Andrew's escape: psychotherapeutic \\ intervention
}

Catarina Pinheiro MOTA ${ }^{1,2}$

\section{Resumo}

O presente estudo de caso aborda a problemática inerente à vivência de um adolescente de 15 anos de idade, marcada pelo desencontro entre seu eu (em formação) e o contexto que o rodeia. Nesse processo de incongruência assiste-se a um progressivo caminhar para o adoecer psicológico, pautado por angústia permanente e sensação de alienação pessoal. A intervenção psicoterapêutica, concebida no Modelo Humanista de acordo com a Psicoterapia Centrada no Cliente, teve por objetivo facilitar a formação de uma identidade saudável, que integrasse as transformações pessoais, as exigências sociais e as expectativas em relação ao futuro. Os resultados revelam um processo de crescimento pessoal e autonomia, marcado pela expressão livre de sentimentos e maior aceitação de si.

Unitermos: Adolescência. Autococeito. Psicoterapia humanista.

\begin{abstract}
The present case study addresses an problem inherent to the experience of a 15-year-old adolescent, marked by a disconnection between his self (in development) and the context that surrounded him. In the process of incongruence one sees a progressive move towards becoming psychologically ill, marked by permanent anguish and a feeling of personal alienation. The aim of psychotherapeutic intervention, conceived in the Humanistic Model, according to Client-Centered Psychotherapy was to facilitate the formation of a healthy identity that would integrate with personal transformations, social demands and future expectations. Results revealed a process of personal growth and autonomy of the adolescent marked by free expression of feelings and better self-acceptance in the surrounding context.
\end{abstract}

Uniterms: Adolescents. Self concept. Humanistic psychotherapy.

Encaminhado a terapia, André (nome fictício) é um adolescente de quinze anos de idade, que vive numa zona urbana do Norte de Portugal, com a mãe, o pai e um irmão de sete anos de idade. Tem condição socioeconômica média-alta, na medida em que seus pais desempenham cargos técnicos superiores. Frequenta o décimo ano da área de Ciências.
André apresenta um desenvolvimento físico considerado normal para sua idade, tem estatura alta e constituição corporal magra, assemelhando uma tipologia longilínea. Denota uma aparência limpa e cuidada, mas se veste de forma particular, principalmente pela roupa bastante apertada e de cor escura, que contrasta com peças de cor muito apelativa e inúmeros adereços,

\section{$\boldsymbol{\nabla \nabla \nabla v}$}

1 Universidade de Trás-os-Montes e Alto Douro, Departamento de Educação e Psicologia. Edifício do CIFOP, R. Dr. Manuel Cardona, Apartado 1013, 5001-558, Vila Real, Portugal. E-mail: <catppmota@utad.pt>

2 Investigadora, Universidade do Porto, Centro de Psicologia. Porto, Portugal. 
como pulseiras e colares. Destaca-se ainda o cabelo irregularmente cortado, de cor negra, muito esticado e comprido na parte frontal, cobrindo os olhos, no estilo "Emo"3, com o qual se identifica. Esse parece ser, entre outros pontos, um foco de discórdia com as figuras parentais, questão que tem gerado conflitos significativos que comprometem sua relação com os pais (sic).

Numa primeira fase da terapia, mantém um contato ocular pouco frequente e realiza pequenas intervenções apenas quando solicitado. Apresenta uma postura relutante, apreensiva e resistente. De acordo com a mãe, André mudara completamente cerca de seis meses antes da terapia, esquivando-se das férias de verão: por um lado, isolando-se mais em casa e passando grande parte do tempo ao computador, em redes sociais; por outro lado, na sua forma de comportamento, na bizarria da roupa e nos estilos musicais (sic). No momento, está de castigo por imposição dos pais, privado de computador e telefone celular, por ter tirado notas baixas e também por terem sido encontrados bilhetes e mensagens via celular trocados com rapazes, revelando uma eventual homossexualidade (sic).

O pai, de 43 anos, apresenta uma postura distante e rígida, e sempre foi uma figura pouco presente na vida de André. Embora morem na mesma casa, André aponta uma ligação frágil com ele, pautada por alguma severidade que lhe causa certa resistência e medo. Por sua vez, a mãe, de 42 anos de idade, assume uma postura de maior proximidade com André, além de uma preocupação exacerbada e ansiedade permanente. Revela indignação e constrangimento em face da mudança do filho, tido até então como figura-modelo, sempre anuente para com os pais e detentor de um excelente rendimento escolar (sic). Sua relação com o irmão de sete anos de idade oscila entre a cumplicidade e conflitos permanentes, pois este "denuncia" aos pais os seus hábitos, assumindo em certa medida uma postura "mimada e manipuladora" (sic). Quanto à família ampliada, André destaca uma relação distante com os avós e tios, especialmente paternos, ressaltando o seu desagrado nas reuniões familiares, em que se sente posto em causa, principalmente pela avó, que assume uma postura muito conservadora e exigente, assim como pelos tios, que oferecem recompensas econômicas para que ele mude de aparência (sic).

André encontra-se mais voltado para o grupo de pares, exclusivamente elementos do sexo feminino, e apenas um rapaz que o acompanha no percurso escolar desde a infância; com eles, refere sentir-se mais livre para "ser ele mesmo". Salienta-se que, quando da primeira consulta, André apresenta comportamento de automutilação, desenvolvido em três episódios, motivado por dificuldades em gerir a frustração, numa "tentativa de fuga" (sic).

\section{Motivo do encaminhamento e pedido de acompanhamento}

André foi encaminhado para a consulta de psicologia clínica pelo médico psiquiatra com o motivo: "... jovem com dificuldades relacionais, isolamento, conflitos com as figuras parentais, alteração da conduta em casa e no contexto escolar, diminuição de rendimento acadêmico e comportamentos de automutilação". Somava-se ao encaminhamento uma indicação de psicoterapia.

O pedido fora feito pelos pais de André, com queixa sobre suas dificuldades acadêmicas e preocupação com sua mudança de atitude, dentre as quais a aparência, a identidade sexual e o comportamento de automutilação.

Ressalta em André uma atitude de revolta e um sentimento de angústia permanente.

\section{História desenvolvimental e familiar}

André é fruto de uma gravidez planeada e desejada. O nascimento deu-se por parto normal, não havendo complicações a ressaltar. A mãe descreve André como um bebê calmo e pouco irritado ao dormir. Teve aleitamento materno até cerca de um ano de idade.

$\boldsymbol{\nabla} \mathbf{\nabla} \boldsymbol{\nabla}$

3 O termo "Emo" é frequentemente usado para significar uma relação particular entre fãs e artistas, além de descrever aspectos relacionados com a moda, cultura e comportamento. Embora não se trate de uma subcultura verdadeira, muitas pessoas adotaram esses aspectos como uma tribo urbana, um estilo de vida. Os seguidores desse estilo sublinham sua sensibilidade e emocionalidade aliada ao estilo e imagem pessoal da roupa (extravagante e apelativa), 
Nunca teve doenças a destacar nem qualquer hospitalização, apresentando níveis de autonomia adequados para a idade. A criança foi sempre cuidada por uma babá, com quem permaneceu até aos três anos de idade, quando ingressou na pré-escola. Apresentou boa adaptação ao novo contexto e revelou-se uma criança obediente, afável e introvertida (sic).

No que respeita ao relacionamento com as figuras parentais, André denotou sempre mais proximidade com a figura materna, mais presente e disponível, com quem gostava de passear e falar de todos os aspectos do seu dia a dia, o que contrasta com a figura paterna que até há um ano antes da terapia exercia a atividade laboral fora da cidade, estando menos presente em sua vida (sic). Ressalta-se o fato de ele nunca ter gostado de atividades comuns ao pai, como jogar bola ou assistir futebol, estando mais disponível para desenvolver atividades com a mãe (sic).

Aos seis anos de idade, André ingressou no primeiro ciclo, apresentando boa adaptação ao contexto escolar, porém com certa resistência e receio diante das brincadeiras mais agressivas dos colegas do sexo masculino (sic). No segundo ciclo, André mudou de escola e, embora mantivesse bom rendimento, manifestou uma ansiedade significativa, fato que parece ter sido reforçado pela figura paterna mais exigente com os resultados acadêmicos.

Aos 12 anos de idade, acentuou-se a diferença de postura de André, principalmente por sua atração física por colegas do mesmo sexo. Esse sentimento foi pautado por um misto de confusão, estranheza, culpa e vergonha, que o levou a ocultar o fato até seis meses antes da terapia. Nessa ocasião, apresentou queda significativa no rendimento escolar, coincidente com a transição para o terceiro ciclo, quando mudou para uma escola diferente, à qual atribui uma conotação de "maior dificuldade".

Os pais de André solicitaram ajuda pedopsiquiátrica e apoio psicológico, havendo um acompanhamento de cerca de um ano, sobre o qual apontam melhorias significativas no rendimento escolar. André descreve-se nesta altura como um conformista, sempre anuente com as figuras parentais, um "betinho"4 na forma de estar e vestir, mas pouco satisfeito consigo mesmo (sic). Refere baixa autoestima e falta de coragem para refutar as imposições feitas pelos pais, principalmente em relação a seu aspecto físico e a sua autonomia, que sente posta em causa.

André descreve que, cerca de seis meses antes da terapia, no final do ano letivo, alterou sua relação com as figuras parentais e o contexto social em geral, concretizando sua necessidade de colocar em causa as imposições dos pais e dizer ao mundo que"está cansado de ser como é" (sic). André isolou-se em casa, voltando-se para seu corpo e para a descoberta de novas perspectivas de vida. Estabeleceu contatos através de várias redes sociais, chamando-Ihe a atenção a irreverência de alguns "amigos" que adotavam o estilo "Emo". André parece ter-se identificado com alguns aspectos dessa subcultura que contrastam com sua realidade, desenvolvendo progressivamente um estilo pessoal que the pareceu mais libertador (sic), mas que em paralelo criou conflitos significativos com o contexto, realçando o sentimento de exclusão e a intolerância à frustração, que ele tem gerido por meio da automutilação.

Destaca-se, para além da mudança de aparência física, a necessidade de afirmação emocional. André mantém uma postura distante e apática com os pais, o que contrasta com a atitude apelativa e exuberante que apresenta no contexto escolar, especialmente quando se sente protegido por seu pequeno grupo de pares.

\section{Avaliação psicológica}

A vivência de André deixa adivinhar um sofrimento significativo ocasionado pelo sentimento de aprisionamento, incompreensão e revolta, mas, ao mesmo tempo, o medo de perda das figuras significativas de afeto. Embora desde cedo sentisse alguma diferença em relação a seus pares de sexo masculino, André parecia gerir essa divergência através do suporte materno e da "fuga" de contextos tidos como ameaçadores. Desse modo, harmonizar-se com as figuras parentais constituiu uma estratégia de proteção que Ihe dava certa segurança.

\section{Q V}

"A gíria lusitana "betinho" corresponde no Brasil a "mauricinho". Indica um homem jovem, bem posicionado financeiramente e excessivamente arrumado na 
À medida que a puberdade se aproximava, André pareceu sentir mudanças na forma de perceber sua relação com os demais. Destaca-se sua relação com rapazes pelos quais sentia uma "afinidade especial" (sic), menos pautada pelo companheirismo e mais voltada para um desejo de proximidade emocional. Escondeu esse sentimento desde então, pela confusão, vergonha e, acima de tudo, pelo medo de rejeição; essa questão constitui um dos principais motivos de conflito com as figuras parentais. Cerca de seis meses antes da terapia André sinalizou "não aguentar mais", tornando urgente a mudança (sic); no entanto, a transição profunda envolvida nesse processo parece ter gerado constrangimentos significativos em sua relação com o contexto familiar e escolar. Se, por um lado, André pareceu sentir-se mais genuíno, por outro, sentia-se incompreendido e rejeitado, fato que lhe acarretou um sentimento de revolta e insatisfação permanente.

A avaliação foi realizada na primeira sessão, num contínuo de conhecimento de si, que foi sendo construído ao longo de vários encontros, sem necessidade de recurso à psicometria ${ }^{5}$, coadunando-se com uma atitude interventiva que se inicia desde logo, ante $\mathrm{o}$ mal-estar que André evidencia. A apreensão e resistência de André surgem em paralelo à atitude da mãe, visivelmente ansiosa e autoritária, que expõe nessa primeira sessão um desejo de mudança do filho para"voltar a ser o que era".

André mantém pouco contato ocular e encolhe os ombros numa atitude pouco concordante. Apesar do pedido explícito das figuras parentais, é pertinente esclarecer a ele seu papel como paciente, enfatizando a importância de comparecer à consulta. Esse esclarecimento é realizado ainda na primeira sessão, já sem a presença das figuras parentais, quando André se mostra mais expressivo. Aponta seu mal-estar diante da falta de aceitação e, sobretudo, da invasão de privacidade de que se sente alvo ("... todos os dias revistam a minha mochila para ver se tenho bilhetes de rapazes... não posso sair sozinho... e não me dão dinheiro para eu não telefonar a ninguém, nem comprar coisas para mim!'). Assume uma mudança radical, mas necessária, que lhe tem acarretado conflitos permanentes (sic). Embora ainda resistente, André menciona sua dificuldade em gerir a relação com o contexto que o rodeia, especialmente com as figuras parentais, de modo que seu pedido não vai na mesma direção do desejo deles, mas sim no sentido de poder "viver a sua vida".

Note-se que as transições que experimenta parecem ter dado a André uma sensação de maior liberdade, gerando energia, criatividade e sobretudo fantasia, típicas da fase desenvolvimental de formação da identidade que atravessa. Essa questão evidencia-se particularmente no domínio afetivo com o par amoroso, pautado pela idealização em torno da felicidade. André investe nas relações com rapazes através das redes sociais, na tentativa de encontrar a realização de sua identidade sexual e ao mesmo tempo um suporte afetivo. Todavia, manifesta uma significativa intolerância à frustração, que tem canalizado para a automutilação em três episódios distintos, ao que acresce um quarto episódio depois de uma discussão com a mãe. Essa atitude é descrita como uma tentativa de fuga diante do sofrimento emocional ${ }^{6}$ (sic), ficando excluída a ideia de tentativa de suicídio associada.

Fica evidente que André sente necessidade de ajuda, muito embora seu pedido seja pouco claro, assim como as ideias e sentimentos que traduz, lábeis e bastante marcados pela incerteza. Fica patente um sentimento de angústia e fragilidade interna, que inunda sua vivência, repleta de exploração de alternativas e compromissos de escolha que parecem uma tarefa arriscada no seio de uma insegurança pessoal.

Foi realizada uma devolução compreensiva dos resultados com André e os pais, ficando acordada por todos a pertinência de ele iniciar um processo terapêutico. Não houve contato posterior com os pais.

$\boldsymbol{\nabla} \nabla \boldsymbol{\nabla} \nabla$

5 Quando do encaminhamento do médico psiquiatra, foi enviado um relatório da avaliação psicológica realizada mediante entrevista clínica e da aplicação do Inventário Multifásico de Personalidade de Minesota (MMPI-2), com informação acerca da necessidade de manter uma boa imagem de si e alguma rigidez evidente. Os resultados relatados vão ao encontro da análise até aqui realizada, acrescentando informação acerca de um estado de confusão interna, tristeza e insatisfação com a vida, mas sem atingir o estado depressivo, já que André mantém a atividade, energia, esperança e criatividade (ligeira elevação da escala de hipomania). Apesar da incerteza, a mudança parece ter-lhe trazido alguma confiança em si, pelo fato de se sentir mais como agente racional de seu percurso desenvolvimental.

- A automutilação constitui uma prática frequentemente associada à subcultura emo com a qual André se identifica, preconizando a exacerbação da 812 sensibilidade e a atenuação do sofrimento através da dor física. 


\section{Diagnóstico psicológico}

O conhecimento mais profundo de André sugere um adolescente com acentuada agitação interna, dividido entre, de um lado, desejo de autonomia, vivacidade, esperança e criatividade (expressas na mudança radical de comportamento, aparência e afirmação da identidade sexual) e, de outro lado, incompreensão, incerteza e revolta (pela não aceitação, invasão pessoal e menosprezo experimentados, especialmente advindos das figuras parentais). Percebe-se nele uma difusão da identidade, uma procura do eu ainda confuso e em processo de construção; por isso experimenta e desafia em vários domínios, na tentativa de encontrar o bem-estar pessoal.

A decisão de mudar parece ter trazido a André uma satisfação significativa pela percepção de que é agente ativo de sua vida. Todavia, sente-se inseguro e resistente perante a sensação de rejeição que Ihe é dolorosa. Manifesta defensividade, negando a necessidade de apoio exterior, principalmente ante o investimento afetivo dos pais - ao mesmo tempo que, no seu íntimo, sente medo de perdê-los e lamenta defraudar suas figuras significativas de afeto, apesar de desidealizá-los (processo necessário nessa fase desenvolvimental).

Nessa medida, direciona grande parte de seus investimentos para os pares mais disponíveis e aceitantes de sua diferença. Explora a relação com o par amoroso com um investimento muito significativo, bastante fantasiado e idealizado, embora em sua grande maioria frustrado, o que lhe acarreta um sofrimento que tem dificuldade em gerir.

A avaliação realizada não sugere o desenvolvimento de um processo depressivo associado. Todavia, a vivência de André tem sido pautada por uma busca permanente de si, com marcada labilidade emocional, angústia e uma sensação de alienação pessoal. Ao mesmo tempo, percebe-se em André uma baixa autoestima, destacando o seu desconforto face à imagem física (feições de rosto, caracteres sexuais masculinos secundários etc.) e em relação a sua forma de estar (amedrontado e pouco seguro), escondendo-se atrás de uma extroversão parcial e de um comportamento apelativo. Desse modo, André manifesta uma elevada necessidade de pertencimento e integração, de imagens positivas de si e dos outros, de modo a criar condições de consolidação de sua identidade. A continuidade da incon- gruência entre o que sente (no seu eu em formação) e a experiência real pode tornar-se palco de um comprometimento do núcleo estável da personalidade, que, não sendo definitiva, contém um fundo definido de ser sexuado e pessoa social com implicações em sua vivência futura.

\section{Análise compreensiva da problemática}

A transição de André para a adolescência parece ter ocasionado uma necessidade de conhecimento pessoal e reorganização de si, pautada por novas experiências e compromissos de escolhas cujas consequências e responsabilidades constituem um desafio. Sempre considerado o "filho e aluno exemplar" (sic), ele teve um percurso sem sobressaltos comportamentais e sem qualquer tipo de oposição às práticas educacionais, revelando conformidade com sua aparência. Sempre caracterizado como criança introvertida, obediente e até amedrontada, André procurava contextos onde se sentia mais seguro, na maioria suportados por elementos do sexo feminino, como a mãe ou as colegas da escola, que sempre o acompanham e constituem seu reduzido grupo de pares. Sob o ponto de vista emocional, destaca-se a sensibilidade emergente que o caracteriza desde criança, mais voltado para jogos emocionais e atividades de interação social. Mantém uma relação de grande proximidade com a figura materna, ao invés do pai, tido como figura de autoridade com quem sempre manifestou relutância em dialogar (sic).

Com cerca de 12 anos de idade parece haver uma mudança interna que deixa André atento, preocupado e inclusive culpabilizado. Sua relação com os pares do mesmo sexo assume um aspecto diferente, caracterizado pelo desejo de envolvimento afetivo que inicialmente cria nele certa estranheza, que guarda numa fortaleza da solidão. Ao longo do tempo esse sentimento parece consolidar-se, desenvolvendo uma angústia de aprisionamento diante do receio de abordar o tema, sob pena de renúncia social. Do mesmo modo, inicia uma compreensão mais crítica do mundo que o rodeia, o que se coaduna com a conquista da individuação, o crescimento da autonomia e o início da formação da identidade. 
Por conseguinte, André realiza um luto dos imagos parentais, desidealizando e questionando as figura parentais, que oscilam na sua representação entre a base segura7 e uma barreira para a individuação. A individuação envolve a separação psicológica dos pais reais e dos pais idealizados, de modo que, à medida que a individuação se processa, a autonomia cresce (Blos, 1979). André afasta-se da postura de dependência, individuando-se, e se aproxima de uma liberdade pessoal (ainda que condicionada), autonomizando-se.

Embora atualmente tomado pelo sentimento de revolta, André sentiu desde criança uma dinâmica de proximidade e segurança trazida pelas figuras parentais que constituem efetivamente a sua base segura. A transição para a adolescência recria mudanças ideológicas, comportamentais e sociais que traduzem uma necessidade de exploração e libertação. Todavia, o aspecto de irreverência dessas mudanças parece entrar em conflito com as diferenças geracionais e estereótipos sociais dos pais, provocando desencontros emocionais de ambas as partes. Por um lado, os pais mostram resistência a uma mudança extrema, pouco aceitável e injustificada (sic), e, por outro lado, André sente o desapontamento de não ter a oportunidade de livre escolha e aceitação das pessoas que são mais importantes para ele. Essa incongruência gera em André um sentimento de angústia e uma vivência ansiosa do dia a dia.

Apesar dos esforços para se livrarem das dependências infantis, em alguns casos os adolescentes desenvolvem modalidades de separação que podem inviabilizar a separação interna, como forçar a separação física, moral e ideativa (Fleming, 2005). Embora se refugie numa postura de falsa indiferença e confronto permanente, André sente o seu processo de separação-individuação comprometido, devido à falta de confiança dos pais e à permanente infantilização de si mesmo. Para ele, a disponibilidade das figuras parentais encontra-se quase totalmente ausente, remetendo-o a modelos negativos de si próprio, desmerecedores de atenção, carinho e, sobretudo, respeito (Bretherton, 2000).

Dessa forma, o sentimento básico que André experimenta é a decepção com o contexto em que vive e, em especial, com as suas figuras significativas de afeto. Rejeita frequentemente a necessidade de afeto dos pais ("gostava que eles não existissem...") e logo reconsidera seu sentimento ("...ou que tivesse outros diferentes... que não fossem injustos comigo e me compreendessem"). Entende-se que André tem um forte desejo de reconciliação e de manutenção dos laços afetivos com as figuras parentais, com necessidade de voltar a estar próximo à mãe numa ligação de apoio e confidencialidade, e com urgência de integrar uma relação positiva com o pai, numa dinâmica de afeto que se contrapõe à rejeição que foi construindo em relação a ele.

Paralelamente procura encontrar o apoio necessário no grupo de pares, tido como porto seguro, embora limitado a poucos elementos, quase exclusivamente garotas, com as quais se sente mais aceito e compreendido. Nesse contexto, através de comportamentos de autonomia, André ensaia papéis e adquire habilidades de intimidade, além de enfrentar desafios que definem sua identidade e se incorporam a ela (Erikson, 1968). 0 contexto escolar torna-se palco para essa experiência; aí, André sente ser ele próprio, ao invés da postura adotada dentro de casa, com os pais.

Sua extroversão e comportamentos bizarros conduzem a uma postura permanentemente apelativa que se assume diante dos professores e colegas de turma, mas que esmorece quando ele está sozinho. Essa vivência assinala uma significativa insegurança, que parece ainda demasiado dependente das experiências que vive e dos significados pessoais que the atribui e que, em alguns casos, não tolera. A vivência de frustrações reforça os sentimentos de insegurança e revolta, que André canaliza direta ou indiretamente para a autodestruição.

Embora estejam patentes outras dificuldades na existência de André, a automutilação constitui uma preocupação real, ocorrida em quatro episódios, na maioria em contextos de desilusões afetivas relacionadas com a identidade sexual. Essa agressividade ilustra sua dificuldade em (r)estabelecer a ligação com os outros, ou seja, o ataque ao próprio corpo expressa o

7 A base segura implica o sentimento de confiança em si mesmo, associado à elaboração de uma correspondência afetiva por parte de uma figura de apoio e proteção, acessível e disponível (Bowlby, 1988). 
questionamento de sua relação com ele, traduzindo a fuga de uma situação sentida como insuportável. A necessidade de domínio do corpo, quando suas incessantes mudanças dão ao adolescente a dolorosa impressão de não ser seu dono, ocasiona a vivência de um agente estranho sobre o qual podem focalizar-se as tendências agressivas e destrutivas (Marcelli \& Braconnier, 1989). De acordo com Matos (2002), a vivência de angústia e sofrimento é muitas vezes colmatada em forma de ação, funcionando como a procura de um elemento continente.

Não obstante André insinue sua convicção quanto a sua identidade sexual, a relação que desenvolveu com os elementos do sexo masculino é pautada pela vergonha e receio de rejeição, ao mesmo tempo que vive uma necessidade (secreta) de aproximação permanente. Ao assumir sua homossexualidade perante si mesmo e perante os outros, André cria um aparente sentimento de acalmia e libertação pessoal, porém, no íntimo, marcado pelo temor da exclusão e pela cultura da crueldade. Atribui esse sentimento ao fato de se sentir rodeado por um extremo conservadorismo, machismo e intolerância da sociedade, especialmente "numa cidade pequena de interior" (sic).

A introjeção das atitudes negativas que o rodeiam soma-se a uma experiência distorcida, como se fosse baseada em conclusões alcançadas pelo próprio organismo do indivíduo (Rogers, 1974). Percebe-se em André uma vulnerabilidade afetiva, seguida de um estado de confusão mental ocasionado pelas inúmeras experiências e compromissos que tem assumido nos últimos tempos. Fica patente a subsistência da ligação aos pais e uma necessidade de organização interna e crescimento pessoal de acordo com as mudanças desenvolvimentais, com vista à autonomia e à formação da identidade.

\section{Objetivo da terapia}

A compreensão da vivência de André sugere uma agitação interna e um sentimento de angústia permanente. Seu estado emocional revela labilidade afetiva, com oscilações de humor que variam de acordo com as experiências e compromissos assumidos, bem como pela significação atribuída de realização pessoal. Trata-se de um jovem com baixa autoestima e insegurança pessoal, porém esses aspectos são encobertos por alterações comportamentais como oposição, exuberância e apelação. Manifesta um isolamento significativo diante do contexto emocional que o rodeia, destacando a incompreensão e revolta com suas figuras significativas de afeto, com as quais se sente severamente decepcionado.

André apresenta um self imaturo, em processo de organização, e uma vulnerabilidade ${ }^{8}$ emergente. 0 mal-estar provocado pela percepção de insegurança recria uma imagem negativa de si e dos outros, que o conduz a uma contínua organização defensiva. A intervenção psicoterapêutica torna-se relevante, dado o sofrimento manifestado por ele, que vive entre idealizações, conquistas e retrocessos. André apresenta uma elevada intolerância à frustração, o que o tem conduzido a processos de destruição pessoal e adoecer psicológico. Entende-se que, durante a psicoterapia individual, suas necessidades poderão girar em torno da dinâmica da formação da identidade, encarada como um processo integrador das transformações pessoais, exigências sociais e expectativas em relação ao futuro, condições que se encontram significativamente comprometidas nesse momento.

\section{Processo psicoterapêutico}

O processo de acompanhamento durou um ano e meio, com sessões semanais nos seis primeiros meses e, depois, quinzenais, com duração média de 45 minutos aproximadamente. Diante da compreensão de André, julgou-se pertinente uma intervenção psicoterapêutica individual, com vistas a seu crescimento pessoal. O processo psicoterapêutico foi aceito, diante do sentimento de incongruência e da necessidade de mudança.

O modelo psicoterapêutico adotado foi o Humanista - Centrado no Cliente, criando condições suficientes para que André experimentasse a liberdade de

$\boldsymbol{\nabla \nabla \boldsymbol { V } \boldsymbol { V }}$

- A vulnerabilidade representa o estado de desacordo que pode existir entre o"eu"(em formação) e a experiência. O sujeito está em perigo de desorganização psíquica, especialmente quando se encontra em estado de desacordo sem se dar conta disso, estando assim mais suscetível à angústia, à ameaça e à desorganização (Rogers \& Kinget, 1975). 
"ser ele mesmo". A agitação e angústia sentidas por ele ocasionaram a necessidade de encontrar um espaço de aceitação incondicional, capaz de facilitar a clarificação dos sentimentos e a descoberta de si.

Num primeiro momento, a primeira sessão traduz uma postura defensiva por parte de André, que comparece à consulta de psicologia clínica por imposição dos pais. Denota um constrangimento permanente ante os relatos de indignação e críticas extremadas realizadas pela mãe.

O pedido dos pais gira em torno da sua mudança de aparência, que constitui um foco de atenção, bem como do decréscimo no rendimento escolar. Outras queixas são o isolamento e a falta de comunicação, em especial com a mãe, que outrora valorizava a disponibilidade de André. Finalmente e talvez a questão que constitui o centro mais significativo do embaraço parental: a suposta homossexualidade de André ("esta mania que the deu agora de gostar de rapazes!").

O rapaz mostra-se pouco concordante e nada interventivo. Ainda nessa sessão, apenas com a presença de André, é-Ihe feito o convite para falar daquilo que está acontecendo com ele. André relata uma mudança grande desde as férias (seis meses antes da terapia), ocasionada pelo seu cansaço de ser "direitinho" e não se sentir ele mesmo. Aponta a urgência dessa mudança pelo sentimento de aprisionamento que vem sentindo já há cerca de três anos antes da terapia, quando "comecei a ter mais crítica de mim e a perceber que era diferente". O isolamento constituiu o tema para a descoberta de um novo "eu", enquanto as redes sociais e a informação trazida pela Internet constituíram um veículo de conhecimento e identificação com outras formas de estar.

Nessa fase, o experimentar exerce um papel preponderante, dando lugar a uma libertação demasiado exposta de si mesmo. André descreve a mudança como "demasiado radical", provocando um controle exacerbado por parte dos pais. Ao contrário deles, André rejeita a ideia de voltar a ser o que era, e seu pedido se organiza em torno de "viver a sua vida e ser feliz". Clarificando o pedido, André acrescenta que gostaria de ser mais compreendido e deixar de ser tão controlado, como se fosse uma criança (sic). Aponta ainda a desconfiança permanente dos pais que repudiam suas manifestações 816 de identidade sexual, distinta do esperado e em con- fronto com as ideias conservadoras deles. Nessa fase, André mostra-se confrontativo ante a atitude dos pais ("...quanto mais me proíbem piorfaço! A minha mãe dizque estou algo melhor mas é porque não dou tanto nas vistas na frente deles! Continuo a maquiar-me na escola e a usar pulseiras de cores, mas quando chego a casa escondo tudo!'). André aponta ainda que está cansado de "visitar" médicos, psiquiatras e psicólogos, quase como se o fizessem sentir-se um problema, sendo obrigado a expor sua intimidade, o que talvez fosse importante, mas o deixava pouco à vontade (sic).

Ao longo dessa sessão fica patente em André a vontade de ser ajudado, não por se considerar um problema, mas talvez pela estranheza que sente por parte do contexto que olha para ele. O medo, a confusão interna e a insegurança tomam conta dele, que, apesar de sua postura de confrontação, sente-se frágil.

Nesse sentido, é esclarecida a André a relevância de seu papel para o processo: muito além das angústias parentais, importa criar um espaço para ele, onde possa sentir-se ajudado, sem julgamentos, imposições ou indicações capazes de condicionar a sua necessidade de crescimento.

Na terceira sessão é proposto a André o ingresso no processo psicoterapêutico, ao encontro de seu pedido, que parece agora mais claro. Ele concorda com a ideia, ficando implícita a necessidade de uma reavaliação periódica do processo, principalmente quanto ao sentido que ele encontra na terapia.

As sessões que se seguem constituem um espaço em que André aborda as discussões que tem vivenciado com as figuras parentais. Encontra-se mais disponível para falar de si, percebe o lugar da terapia como seguro, e a relação terapêutica adquire cada vez mais um aspecto de empatia, autenticidade e transparência. André experimenta momentos de profundidade relacional que Ihe traduzem a sensação de ser merecedor de confiança, verdadeiro e sincero no seu desejo de compreensão (Knox\& Cooper, 2011).

Denota uma marcada revolta e um sentimento de injustiça, e a ideia de falar diretamente com os pais acerca dos seus sentimentos constitui algo utópico, embora desejado na tentativa interna de uma resolução. A figura paterna é especialmente retrativa para André, já que, para além de intimidação, reporta-lhe temor. 0 controle exacerbado e o castigo de que é alvo deixam-no decepcionado, isolado de todos (sic), sem telefone 
celular, sem computador e com as saídas cronometradas; sente a sua vida social acabada (sic). Nesse sentido, André mostra vontade de fugir ("deixar tudo!").

Fala, então, de sua dificuldade de ultrapassar barreiras, de modo que a frustração provoca-lhe vontade de magoar a si próprio, numa tentativa paradoxal de resolver o problema. Em três episódios a automutilação nos braços ocorrera após desencontros amorosos com rapazes, a maioria conhecidos através da Internet, o quarto episódio aconteceu nessa semana, precisamente depois de uma discussão com a mãe. Essa questão constitui um perigo autêntico para André; embora não tenha intenções suicidas, a forma que encontra para colmatar o sofrimento coloca em causa seu bem-estar físico e emocional que, de qualquer forma, o conduz a um adoecer psicológico emergente.

É devolvida a André a dimensão de sua dor, mais além do que no plano físico, sente-se emocionalmente magoado e, sobretudo, confuso e sozinho. A solidão parece ser vivenciada por ele através de uma brecha fatal em que a maior parte do comportamento é regulada em termos de significados percebidos na consciência, enquanto outros significados são negados e descartados, por incapacidade de comunicação consigo mesmo (Rogers, 2002). Fica patente nele uma labilidade emocional significativa e um desejo de ser acolhido e aceito em seu sofrimento.

A quinta sessão é marcada por uma alteração no humor de André. Surge pela primeira vez sorridente, referindo de imediato que a relação com os pais tem melhorado (sic). Foi devolvida a André a percepção de seu desejo de reconciliação com as figuras parentais, que mantém no íntimo, como se a aceitação dos mesmos fosse uma peça-chave de sua felicidade. Comenta que tem saído com a mãe para andar a pé e fez recente visita a sua aldeia (dela), o que Ihe propiciou um bem-estar significativo, especialmente porque sentiu uma confirmação direta da sua fantasia de ser querido e desejado pelos pais ("... vou a todo lado com tal de te verfeliz...").

Por outro lado, André mostra ainda alguma desconfiança, já que os pais Ihe propuseram de novo um acesso ao telefone celular e à Internet ("aposto que me querem controlar!"). É esclarecido a André que "... afinal o pai e a mãe mostram que gostam de ti e tu pareces saber disso, mas é estranho para ti que eles queiram confiar em ti". André parece ainda não estar preparado para que confiem nele, por não se sentir completamente genuíno; sugere haver ainda um desencontro entre aquilo que acha que os pais esperam dele e o que ele está disposto a oferecer; a mudança é algo de que não está disposto a abdicar; por outro lado, sente que seu (r)enquadramento emocional é urgente.

No período que segue, André parece realizar um esforço para recuperar a relação com os pais. Embora ainda renitente, vive numa emergência de sentimentos que ao mesmo tempo o aproximam e distanciam deles (sic). As férias da Páscoa coincidem com a entrega dos resultados escolares, que desapontam as figuras parentais (sic), especialmente a mãe, que se mostra ansiosa e desiludida. Percebe-se nessa fase um André triste por não corresponder às expectativas. Apresenta resultados negativos em matemática e, inesperadamente, em Educação Física, fato que não havia comunicado aos pais.

Essa nota se explica, de acordo com André, por sua persistente falta de vontade de ir às aulas, especificamente ter que se vestir e despir no vestiário dos rapazes, por olhar e sentir-se olhado pelos demais rapazes (sic). Trata-se de uma questão significativa, mas que André não quer abordar ("... não me sinto bem a falar disso!"). Ele manifesta uma extrema proximidade com o sexo feminino, identifica-se nas roupas e na forma de estar e de ser (sic). Denota vergonha em torno dos caracteres sexuais secundários masculinos que experimenta, principalmente o crescimento da barba e dos pelos nas pernas e braços, que insiste em esconder. Encontra-se numa fase importante na formação de sua identidade, com necessidade de descobrir, ocasião em que as relações pessoais assumem um papel importante, assim como a imagem corporal.

A confusão e labilidade emocional que vive remetem para as mudanças que vive no dia a dia e que em nada se distanciam de um processo dito "normal". Nessa fase de construção de si, todavia, o maior risco se refere à vivência da sexualidade escondida e envergonhada, que ele teme constituir alvo de rejeição.

Quando da décima terceira sessão, André menciona sua recente experiência homossexual, mais real (sic) e pautada por uma proximidade física concreta ("um primeiro beijo"). Mais uma vez, ele recorrera a redes sociais na Internet para estabelecer contato com rapazes, que nesse caso acaba por se concretizar fora de sua cidade. O fato ocorreu durante uma excursão escolar, que lhe proporcionou o espaço de encontro num shopping. A vivência dessa experiência recria em André 
um misto de euforia e de insegurança ("... os colegas e professores ficaram perplexos, não me importa... ele protegeu-me ... foi bom, senti realização..."). Note-se que André parece algo reticente diante do julgamento de que tem sido alvo desde então, já que se torna pública para a escola a sua identidade sexual; muito embora ele tente transparecer indiferença, fantasia com a ideia de mudar de contexto ("... estou farto de estar aqui, mudar para uma cidade maior podia ser a minha libertação!'). Portanto, refugia-se numa falsa aceitação de sua experiência como se ela fizesse já parte de si, mas interioriza sentimentos negativos que fortalecem sua vulnerabilidade pessoal e o desenvolvimento de um estado incongruente (Lietaer, 1993).

André parece sentir-se cada vez mais disponível no espaço de terapia, onde é incondicionalmente aceito e compreendido. A resistência que se fazia sentir outrora surge agora mais tênue, sugerindo o desenvolvimento de uma aliança terapêutica. Nessa fase, embora ainda com uma significativa labilidade emocional frente às vivências que experimenta, parece estar mais voltado para a resolução de seus conflitos internos, agora mais tolerados e melhor geridos.

Abandona os comportamentos de automutilação, que considera nesse momento inoportunos e capazes de causar sofrimento aos demais que gostam dele ("... os meus pais ficam preocupados e as minhas amigas dizem que é uma estupidez e se volto a fazer não me falam mais... eu também concordo!"). Essa questão é devolvida a André, reformulando a capacidade que agora mostra em tolerar o sofrimento de outras formas e o reconhecimento de que afinal há pessoas que gostam dele e lhe querem bem.

André mostra-se concordante e realizado com a ideia, apontando ainda sua necessidade de fazer "as pazes" com muitos aspectos de sua vida. A relação parental é sem dúvida uma delas, agora menos pautada por conflitos. André surge menos confrontativo e capaz de sentir esperança na relação, o que se associa ao fato de não se sentir tão agredido com sua aparência física, embora ela seja desvalorizada pelos pais. A questão é menos acentuada para André, que volta a comprar roupa com a mãe e acede em cortar parcialmente o cabelo (sic). Todavia, permanece ainda um medo em André: a aceitação de sua identidade sexual.

Na vigésima sessão, André reflete em torno da 818 relação que vem mantendo com as figuras parentais:
... a minha mãe sempre me apoiou em tudo... o meu pai é mau e magoa-me muito... aos nove anos lembro-me de me bater bastante e agora magoa-me psicologicamente... sinto nojo por ele, não me agarro a ele... não consigo... a minha mãe agora também me magoa... diz que preferia que eu fosse tudo menos isso (homossexual)! Mas mesmo assim consigo agarrar-me a ela!

Seu sofrimento parece bem patente: para além da revolta e da injustiça, teme acima de tudo a perda do amor dos pais. A ideia de desiludir a mãe parece ser pouco suportada por André, acarretando nele certa culpabilidade. No que concerne ao pai, sugere desenvolver um desejo escondido de reconciliação versus rejeição, como se ambicionasse que a figura paterna estivesse disponível para cuidar dele, mas, ao mesmo tempo, na qualidade de símbolo de repressão (mais racional e agressivo), Ihe relembrasse permanentemente a sua vulnerabilidade pessoal. Nessa medida, o desencontro entre a vivência de André e a fantasia dessa relação tem criado um estado de angústia permanente, que vai mais além da desidealização das figuras parentais.

Na vigésima sexta sessão, André confirma o bem-estar que sente no conforto da relação parental. Para além da temática dos pares amorosos, ressaltada em todas as sessões, André surge bastante direcionado para a estabilidade que a relação com os pais Ihe traz. Relata um sonho que o deixa algo inquieto

... sonhei que o meu pai matou a minha melhor amigae
andava atrás de mim a rir-se. O meu irmão e eu desen-
terramos a minha amiga e ele continuou a rir-se... depois
o meu pai disse-me para ligar à minha amiga e ela
atendeu... afinal estava viva.

Acrescenta que tem conversado mais com os pais "de forma civilizada" e que, embora por vezes discuta com o pai, este mais tarde telefona para saber se ele está mais calmo. André evidencia uma clara satisfação pela progressiva desmistificação do fantasma repressor do pai. É-lhe devolvido o fato de que, embora às vezes Ihe pareça que o pai tenha um papel mortal, isso não se confirma na realidade, e afinal o pai até parece preocupar-se com ele. André mostra-se concordante; ainda que parcialmente, talvez tenha iniciado dentro de si um processo de apaziguamento com a figura masculina que domina sua vida, menos repressora e mais sensível.

Por outra parte, sente-se menos caracterizado por ter em certa medida abdicado de sua aparência, 
fato que Ihe diminui a autoestima, mas que é um esforço em prol de "menos confusão em casa" (sic).

A trigésima sessão coincide com o início do $2^{\circ}$ período do $11^{\circ}$ ano. André mostra-se preocupado com seu rendimento escolar e, sobretudo, com a escolha da carreira. Inicialmente pensava em fazer o curso de design de moda, mas mostra uma perspectiva crítica diante do eventual comprometimento de sua sobrevivência econômica. Por outro lado, enfraquece-se a ideia de estudar em Londres, tal como havia planejado ("longe de tudo!"), diante do receio da separação que ele encara agora como mais ameaçadora. Equaciona nesta fase uma concordância com a mãe, seguir o curso de medicina veterinária, não porque tenha uma paixão pela profissão (sic), mas porque gosta de animais e, além disso, a mãe está muito concordante (sic) ("... eu não desgosto do curso e assim consigo resolver dois problemas... também tenho medo de não conseguir nada como designer e depois é pior!').

Nessa fase observa-se um André mais disponível e com um humor mais estável, mas também mais resignado. Parece que a necessidade do amor dos pais é prioritária e o desejo de ser aceito e (re)construir a relação com eles assume um aspecto relevante em sua vida. Considera-se que André se direciona cada vez mais para uma vivência plena; ainda que abdicando de algumas das suas ideias, a aceitação dos demais implica maior confiança em si e maior segurança pessoal.

A trigésima sétima sessão ressalta o desejo de agradar que pauta dia a dia de André e que se reflete agora no seu estilo pessoal, na forma de vestir e na orientação acadêmica futura. Salienta que tem desvalorizado aspectos que antes insistia em acentuar e que nesse momento sente-se cansado de discutir (sic).

Pela primeira vez, ressalta que gostaria de ver os pais felizes (sic) e parece que de algum modo recebe o feed-back desse sentimento, assumindo em si um caráter reparador. Fala com agrado da liberdade de que tem gozado nas saídas com os pares e na confiança que sente que a mãe deposita nele ("... hoje vou ao cabeleireiro sozinho, cortar e esticar o cabelo, gostaria de fazer algo diferente, por exemplo pintá-lo, mas não posso defraudar a confiança da minha mãe!').

A transição na forma de estar de André parece ocasionada pelo desejo de cessar uma luta interna que tem vivenciado e que, de alguma forma, traduzia uma instabilidade significativa nele. Embora ainda valorize o aspecto físico - que de fato é uma parte importante na construção de sua identidade -, ele agora parece mais capaz de assumir compromissos e tomar decisões de negociação que the acarretem maior estabilidade na relação com as figuras parentais. André surge visivelmente menos ansioso e revoltado, estando apto a lidar com as dificuldades de forma mais adaptativa. Fala com ilusão na perspectiva de novas experiências com o grupo de pares, principalmente em passar um período de férias de verão com eles ("sozinhos!"), ao que acrescenta a tarefa de passar duas semanas na praia com os pais ("... éuma seca... mas só são duas vezes por ano etem queser!").

Nessa altura, o acompanhamento já dura aproximadamente um ano e meio, e é feita uma interrupção durante as férias de verão, já que André estaria ausente na maioria do tempo. Fica combinado seu regresso após as férias, mas se percebe seu desejo de autonomia frente ao espaço da terapia, bem como sua maior capacidade para suportar as as dificuldades. O grupo de pares constitui para ele um porto seguro com o qual vivencia novas experiências, que lhe conferem maior aceitação e maior segurança.

Essa questão é particularmente interessante na medida em que se assiste ao crescimento pessoal de André, mais seguro e congruente consigo mesmo.

\section{Resultados}

O objetivo inicial do processo psicoterapêutico vai ao encontro de um crescimento pessoal que, para além das vicissitudes, seja capaz de conduzir o paciente ao funcionamento pleno ${ }^{9}$. Considera-se que, embora não tenha atingido o funcionamento pleno, André encontra-se agora mais congruente consigo mesmo, menos defensivo e menos angustiado - portanto, mais

Q

- O funcionamento pleno implica um processo de expansão e maturação de todas as potencialidades de uma pessoa. A pessoa que é psicologicamente livre encaminha-se numa direção que a leva a funcionar de um modo mais aceitante (Rogers, 1985). 
capaz de suportar o sofrimento e de compreender a si mesmo no contexto em que vive.

Mostra-se mais aceitante frente às figuras significativas de afeto, principalmente os pais, com quem (apesar das ainda discussões e discórdias) tenta uma reconciliação. "Quando o indivíduo apreende e aceita num sistema coerente e integrado todas as suas experiências viscerais e sensoriais, necessariamente compreende melhor os outros e aceita-os como pessoas distintas" (Rogers, 1974, p.501).

Essa questão é confirmada por André, que volta à terapia seis meses depois da última sessão. Desde a primeira vez que ele compareceu à consulta de psicologia clínica passaram-se dois anos, e André tem agora 17 anos.

Denota maior estabilidade emocional, mantém um discurso coerente e pouco marcado pela exuberância e labilidade emocional de outrora. Sugere estar menos suscetível às mudanças do grupo de pares, recriando uma opinião mais sólida e segura, que vai além do que os outros esperam. Por outra parte, mostra um desinteresse progressivo pelas redes sociais, quase como se passassem agora para segundo plano, valorizando as saídas reais com as amigas.

Encontra-se algo confuso quanto à escolha a realizar para o futuro, principalmente a orientação vocacional, já que está agora mais próximo dessa realidade, que o assusta (sic). A separação real parece confrontá-lo com uma necessidade de crescimento pessoal, assumindo nessa fase uma postura mais reflexiva em torno do assunto (... por um lado tenho pena e algum medo de sair daqui...").

Ao longo da sessão André mostra-se mais reservado na abordagem de sua identidade sexual, de modo que, apesar de pender marcadamente para os rapazes, assume uma vivência pautada por menos "contratempos" e menor impulsividade. Manifesta nesse momento uma vivência e compreensão de si mais genuína, menos conflituosa e mais aceitante de sentimentos que antes não tinha sido capaz de identificar como seus.

A terapia de André possibilita assistir a um processo de crescimento pessoal pautado por uma arquitetura do self em construção através de maior congruência e autenticidade. André surge mais capaz de organizar suas ideias e especialmente gerir os sentimentos negativos dentro de si, caminhando agora para a autonomia.
A questão da sexualidade é talvez a mais difícil de gerir, inevitavelmente uma barreira para ele, que, nesse momento, omite para proteger os pais, num desencontro entre o desejo de ser aceito e o medo latente de reprovação, especialmente em detrimento deles, os principais agentes de seu suporte afetivo.

Considera-se que André tem ainda um caminho a percorrer na construção da sua identidade. Contudo, fica patente um maior poder pessoal, conferido por uma estrutura mais robusta. Por acordo terapeuta-cliente julgou-se oportuno que André possa agora seguir seu projeto vivencial a solo, ressaltando-se que foram criadas condições para que volte ao contexto de terapia a qualquer tempo. Paralelamente, recebe ainda alta médica por parte do psiquiatra que o acompanhou ao longo do processo.

\section{Referências}

Blos, P. (1979). The adolescent passage. New York: Free Press.

Bowlby, J. (1988). A secure base: parent-child attachment and healthy human development. London: Basic Books.

Bretherton, I. (2000). The origins of attachment theory: John Bowlby and Mary Ainsworth. In S. Goldberg, R. Muir \& J. Herr (Eds.), Attachment theory: social, developmental, and clinical perspectives. London: The Analitic Press.

Erikson, E. H. (1968). Identity: youth and crisis. New York: Norton.

Fleming, M. (2005). Entre o medo e o desejo de crescer: psicologia da adolescência. Porto: Edições Afrontamento.

Knox, R., \& Cooper, M. (2011). Relationship qualities that are associated with moments of relational depth: the client's perspective. Person-Centered and Experiential Psychotherapies, 9 (3), 236-256.

Lietaer, G. (1993). Authenticity, congruence and transparency. In D. Brazier (Ed.), Beyond Carl Rogers. London: Constable.

Marcelli, D., \& Braconnier, A. 1989. Manual de psicopatologia do adolescente. Porto Alegre: Artes Médicas.

Matos, A. C. (2002). Adolescência. Lisboa: Climepsi Editores.

Rogers, C. R. (1974). A terapia centrada no paciente. Lisboa: Moraes Editora.

Rogers, C.R. (1985). Tornar-se pessoa (7a ed.). Lisboa: Moraes Editora.

Rogers, C. R. (2002). Ellen West e solidão. In C. R. Rogers \& R. L. Rosenberg (Eds.), A pessoa como centro (10a ed.). São Paulo: Editora Pedagógica e Universitária.

Rogers, C. R., \& Kinget, M. (1975). Psicoterapia e relações humanas (Vol.1). Belo Horizonte: Interlivros.

Recebido em: 6/10/2011

Versão final em: 21/3/2012

Aprovado em: 17/4/2012 